\title{
Bamboo Joints Review on the Millennium Bridge in Green School Bali
}

\author{
Diego Puja Mring Gusti Han Xiaofeng* \\ School of Architecture, Southeast University, 2 Sipailou Street, Nanjing 210096, P. R. China
}

\begin{abstract}
The Millennium Bridge in Green School Bali is a bamboo bridge building which is a unique building. This structure has local cultural value and has sustainable material. Bamboo, as its material, has been used in traditional way, but become popular lately according with sustainable issue nowadays. In general, this descriptive analytical research will evaluate the bamboo design of The Millennium bridge in The Green School Bali, especially focusing on the joints as constructional material, whether it has already conformed to the literature or not and seek the innovation of the architect for this matter. The analysis will be carried out after surveying the existing state in the form of the photos and making computer model of the researched object, then analyzing the form of the bridge.
\end{abstract}

Keywords: The Millennium bridge, Bamboo bridge, Bamboo, Sustainable material, Green School Bali.

DOI: $10.7176 / \mathrm{ADS} / 91-04$

Publication date:March $31^{\text {st }} 2021$

\section{Introduction}

The Millennium bridge is located inside of the Green School Bali, while The Green School Bali itself, is located in Sibang Kaja Street, Banjar Saren, Abiansemal, Badung district, Bali Island, Indonesia. This facility can be categorized as international school that dedicates to nature, which mean a school focusing on the topic of sustainability and eco-friendly mindset. This school was built by John Hardy and Cynthia Hardy, and they become the founder of this eco-friendly school. The Millennium bridge is the largest bamboo bridge in Asia so far, a kind of wide span construction which has a span of 23 meters with an impressive Minangkabau inspired roof. The architect is Ibuku Architectural Firm, and this building's area is about 45,000 sqm and $70 \mathrm{sqm}$ floor area. This project consumed about 5000 meters bamboo material use as structure. This project met its completion of the construction in December 2011. This bamboo building has the roof structure resembling of Batak tribe traditional house in Sumatra island, Indonesia. This traditional roof represents the symbol of Indonesia identity. As the function as the bridge, The Millennium bridge connects local dweller in Sibang Kaja village to this school, and also has the symbol for educating local people the importance of nature and sustainability.

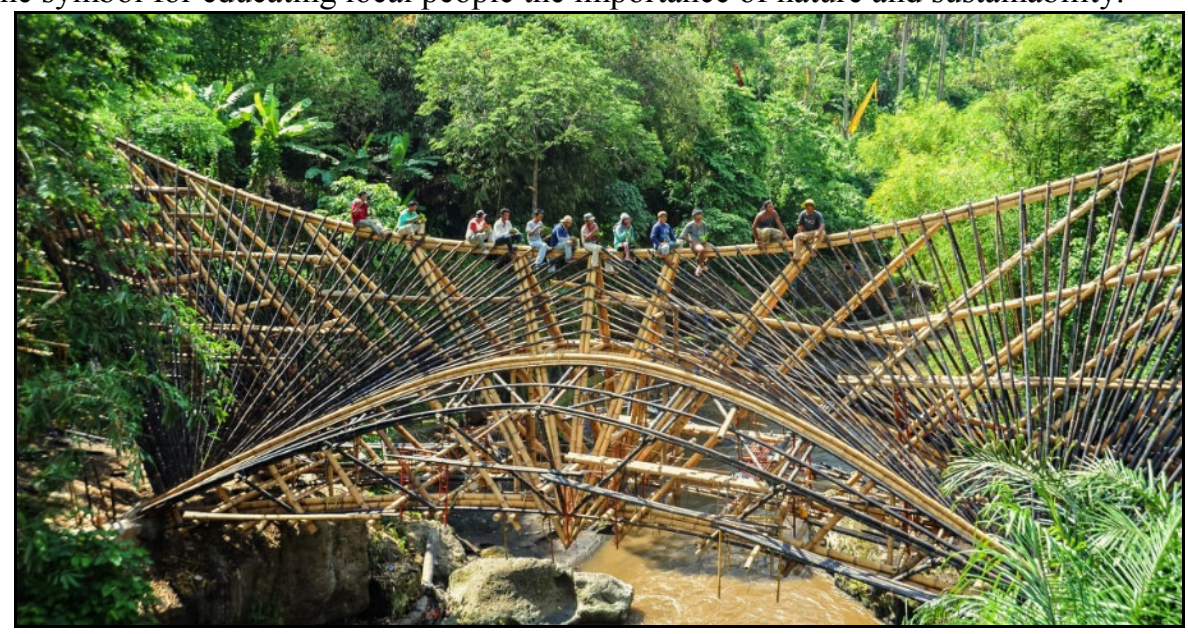

Figure 1: Structure on The Millennium Bridge Bali,

Source: https://ideas.ted.com/gallery-these-buildings-are-made-of-bamboo/

\section{Literature Review}

Jules J.A. Jansen (2000) disclosed, the standard of bamboo construction has to provide improvement in hygiene, to alleviate the suffering and loss in natural disasters such as floods, wind, earthquake, storm, and fire; to meet the owner/occupier needs and as an addition to educate the owner. It means the bamboo needs to be treated well against natural disaster and should use preservation before it applies in as construction. Besides, the bambo as a construction material demand well prepared connection which is so different with woods. Most application with nails just only breaking and destroying the bamboo itself, except the bamboo is drilled firstly (Heinz Frick 2004). 
That's why more complex joints are needed to sustain the whole building. The common connections of bamboo joints mostly using the concept like:

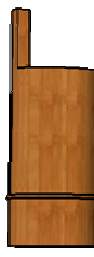

A

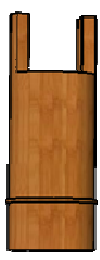

B

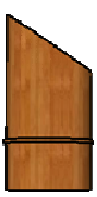

C

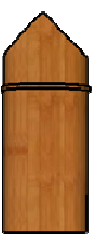

D

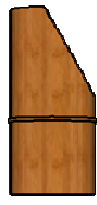

E

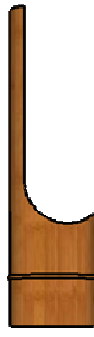

F

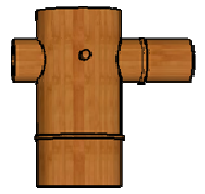

G

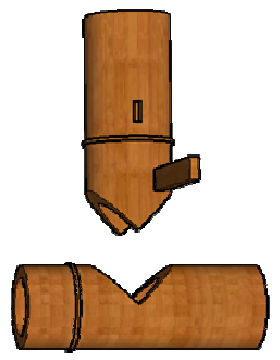

H

Figure 2: Basic Bamboo joints, source: Heinz Frick (2004, p.23)

In the joint $\mathrm{A}$, this is the very basic appearance of the end bamboo joint, it appears very simple, just cut the bamboo stem with one 'ear'. The joint B has double 'ears', it can take compression from a beam. The 'ear' can be a tenon for a hollowed beam and also can be a hold for a beam for falling off. The joint $\mathrm{C}$ has tilted cuts and it appropriate for truss system. The joint $\mathrm{D}$ has a tilted wedge. The joint $\mathrm{E}$ has one part of tilted cut which can also be used in truss system. The joint $\mathrm{F}$ has a long 'ear' that can be bended, this joint is proper for perpendicular joint that engulf the horizontal beam. The joint $G$ is a penetrated horizontal bamboo which has smaller dimension than the vertical part and has mortise-tenon too. The last common joints are the perpendicular joint with wooden pin and wooden dowel/wedge.

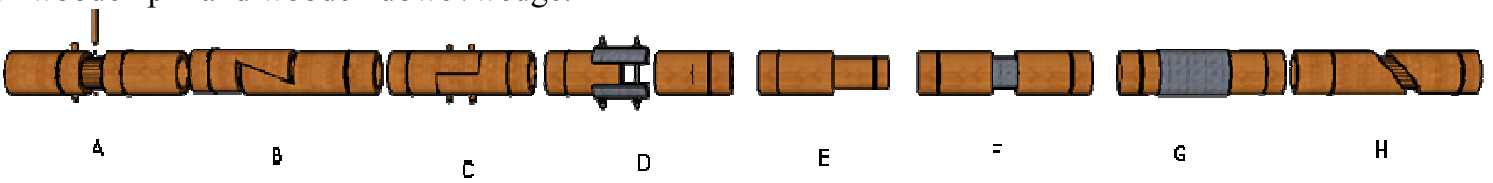

Figure 3: Longitudinal Bamboo Joints, source: Heinz Frick (2004, p.24)

These figure 3's joints are longitudinal joints that are mostly used to lengthen the bamboo stem. The joint A we can see the wooden filler inside the two bamboo stems with double pegs in each parts, the joint with top splicing. The joint B has straight lip joint with lashing. The joint $\mathrm{C}$, the bamboo is joined with curved metal plat with bolts. The joint $\mathrm{D}$ is a simple insertion of non-same dimension of bamboo stems. The insertion technic can be still like in the Joint $\mathrm{E}$ and the joint $\mathrm{F}$ is quite similar with a sleeve. This 'sleeve' bamboo should have bigger size in dimension.

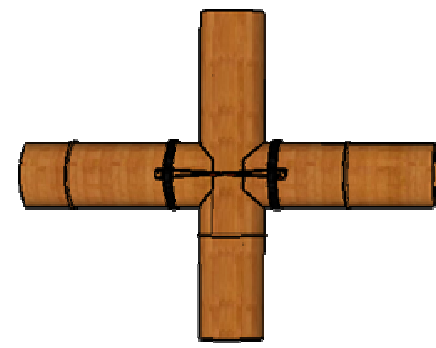

A

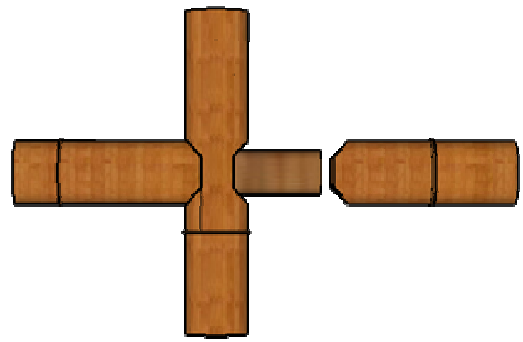

E

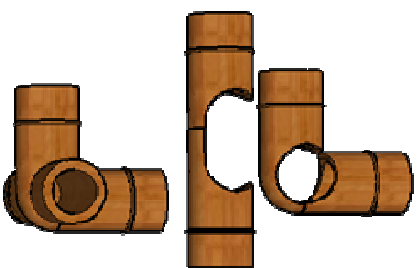

$=$

Figure 4: Cross-section Bamboo Joints, source: Heinz Frick (2004, p.25)

This figure 4 are cross-section joints that involve with peg and lashing for Joint A or with wooden filler inside of longitudinal part, as well like in the joint $\mathrm{B}$. The joint $\mathrm{C}$ is quite different, a part of bamboo is peeled and hollowed, this hollowing process is not for the whole part of bamboo, leaving some part of bamboo culm for bending, and this special part would bend surroundly to other bamboo culm. Bending process in here uses fire/heating, so that it can be bended more easily surrounding another bamboo culm. 


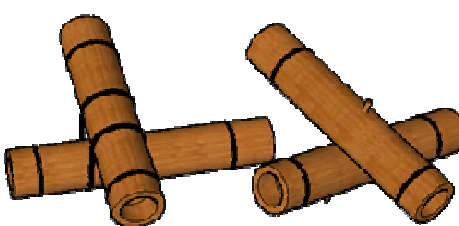

R

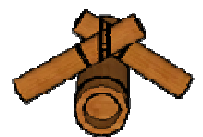

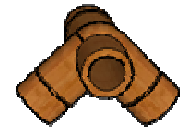

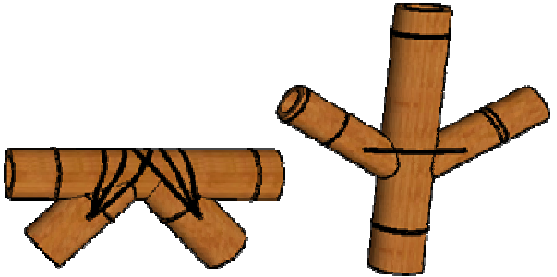

Figure 5: Roof structure Joints, source: Heinz Frick (2004, p.26, 29)

Figure 5's joints are the joints those are mostly found in the roof structure, like an easel and a ridge. First, in the joint $\mathrm{A}$, two parts of bamboo culms connect each other using rope/lashing system. In the joint $\mathrm{B}$, two culms of bamboo meet in cross-section and sticked into one with a dowel in the interconnection. Same with the Joint $\mathrm{C}$, but this joint rests on the bamboo beam and sticked together with the lashing reinforcement, mostly we find this joint in the top of roof structure. While in the joint D, we also can find this on the top of roof structure, one bamboo culm is trimmed a part to engulf the other bamboo culm, it surrounds perfectly. In the Joint E, the connection of the two bamboo culms into another elongated bamboo culm, that is set into horizontal direction. The horizontal bamboo is cut a little bit for the meeting of the other two bamboo culms, these 2 bamboo culms is trimmed in tilted position and pierced a hollow for lashing matter. Lashing in here is mandatory, for the purpose of strengthening the joint and to avoid the horizontal bamboo culm falling off. The joint $\mathrm{F}$, there is a vertical bamboo culm which is peeled off in two sides for the connection of the tilted bamboo culms. These two bamboo culms are also trimmed tilt, and mostly can be found in the easel part.

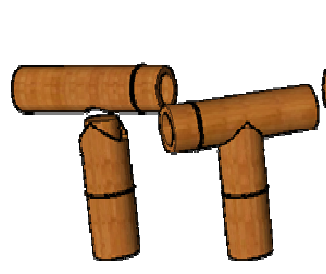

A

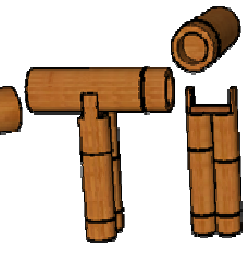

B

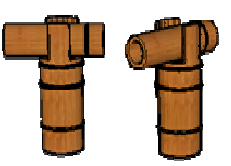

$\mathrm{C}$

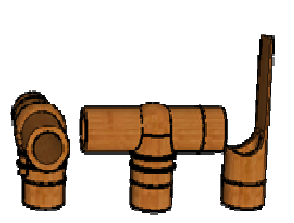

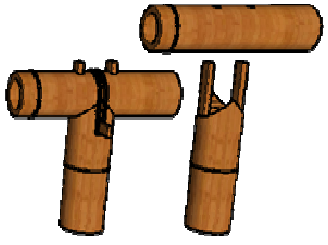

E

Figure 6: Pole-beam Bamboo Joints, source: Heinz Frick (2004, p.25) and Jules J.A. Janssen (2000, p.97)

For these joints, the researcher founded that these joints are for the post-beam connection or for ' $\mathrm{T}$ ' form connection. In the joint $\mathrm{A}$, the beam part is peeled a little bit and the vertical bamboo culm is also cut into tilted wedge's form, inside of this vertical culm is inserted with cylinder made of wood. This insertion is also significant to make the connection firmer. The joint B is quite similar with joint A, but with two vertical culms with one 'ear' in each bamboo culms for avoiding the horizontal culm falls off. The joint $\mathrm{C}$, the vertical bamboo is formed into double ear and putted the horizontal beam part. The joint $\mathrm{D}$, the vertical post part is peeled to make a 'tongue' for the purpose of bending this and engulf the horizontal bamboo culm. For the sake of firming the joint, it can be also added rope. The joint E, the vertical bamboo culm is formed with double dowels and being cut into tilted wedges, these two ears have purpose as tenon part for the horizontal beam.

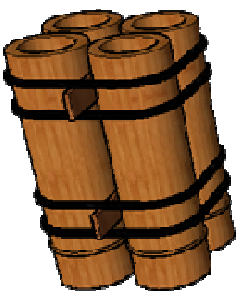

A

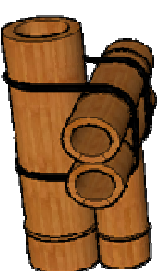

5

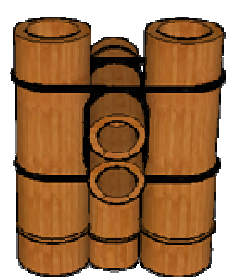

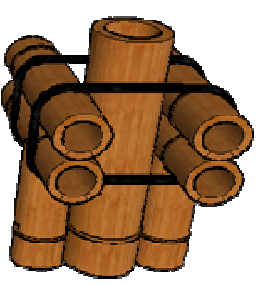

D

Figure 7: Clustered Bamboo Joints, source: https://www.guaduabamboo.com/blog/joining-bamboo

Joints in the poles and columns are important too, regarding bamboo dimension is varied, the system for making these bamboos into poles is put them together into cluster, like in the Joint A, sticking some bamboo culms together with wooden wedges or clamping fitter, makes the columns fitter and better. On the Joint B, Bamboo pole meets bamboo beams with the lashing method in one side. While in the joint $\mathrm{C}$, the bamboo beam is clamped together with two culms of bamboo poles and then sticking them into one system use lashing method. It also quite similar with the joint $\mathrm{D}$, but here the bamboo pole is clamped by two clustered bamboo beams with ropes method. 

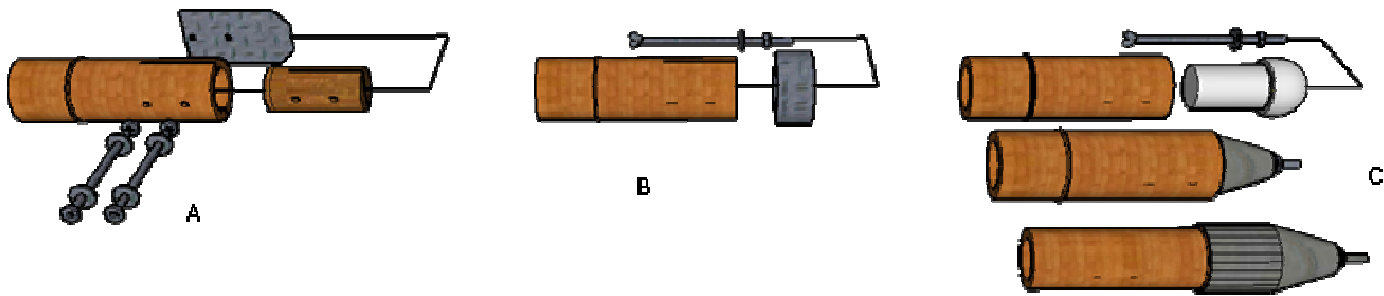

Figure 8: Space frame bamboo joints, source: Heinz Frick (2004, p.27)

As the development of bamboo construction, people tend to create bamboo for space frame structure, and here are the basic connections for space frame structure. In the Joint A, there is a metal plat that is sticked in the wooden $\log$, but this wooden log dimension is smaller than the bamboo culms, when all parts is sticked together there are some bolts or dowels to reinforce them together. While in the joint $\mathrm{B}$, the connection comes from a metal anchor and a clamp for tighten the bamboo culm. The joint $\mathrm{C}$, it is ball joint system, like special connection made of metal that is applied on the end of the bamboo culm, the variation of this system is varied through many companies. In all joints for space frame here can connect into a point that comes from many directions like we can see in the Figure 9 below.
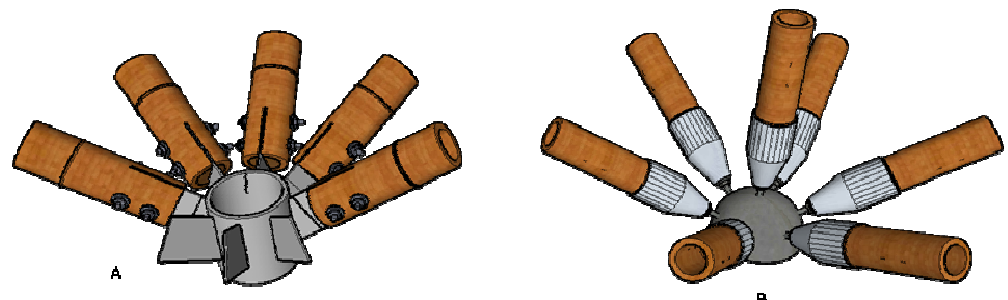

Figure 9: Space frame connection with bamboo, source: Heinz Frick (2004, p.28), Bridgette Meinhold (2011)

As a common system of joints, the most used system is mortise-tenon, the mortise is the hole and the tenon is the tongue. This system is also found in the wood system joints. For addition of the mortise-tenon system, some practitioner also to append with lashing/rope system. The purpose of lashing mostly for rigidity aspect and to avoid the component of bamboo miss slipped or falling to other location.

\section{Analysis and Discussion of Findings}

As Widyowijatnoko (20018) said in wide span building construction, there are at least some aspects that need to be paid attention to solve difficulty, and these are manufacturing, structural interpretation and currency providence aspect. These three aspects are mandatory to construct building, especially wide span building like The Millennium Bridge in Bali. The manufacturing in here is definitely relating to the technical parts like joinery and knowledge in material. Technical joinery and deep understanding in bamboo construction is really important towards achieving good bamboo building, and this is the session of the Millennium bridge's discussion. As the main structure of the bridge is an arch with bamboo material that contains of some bamboo culms, this arch is bended for 23 meters span findings that comes in The Millennium Bridge in Bali, the joints contain of lots of types. There are mortise-tenon system, bolt and foundation joint. Here the figure of the bridge building structure:

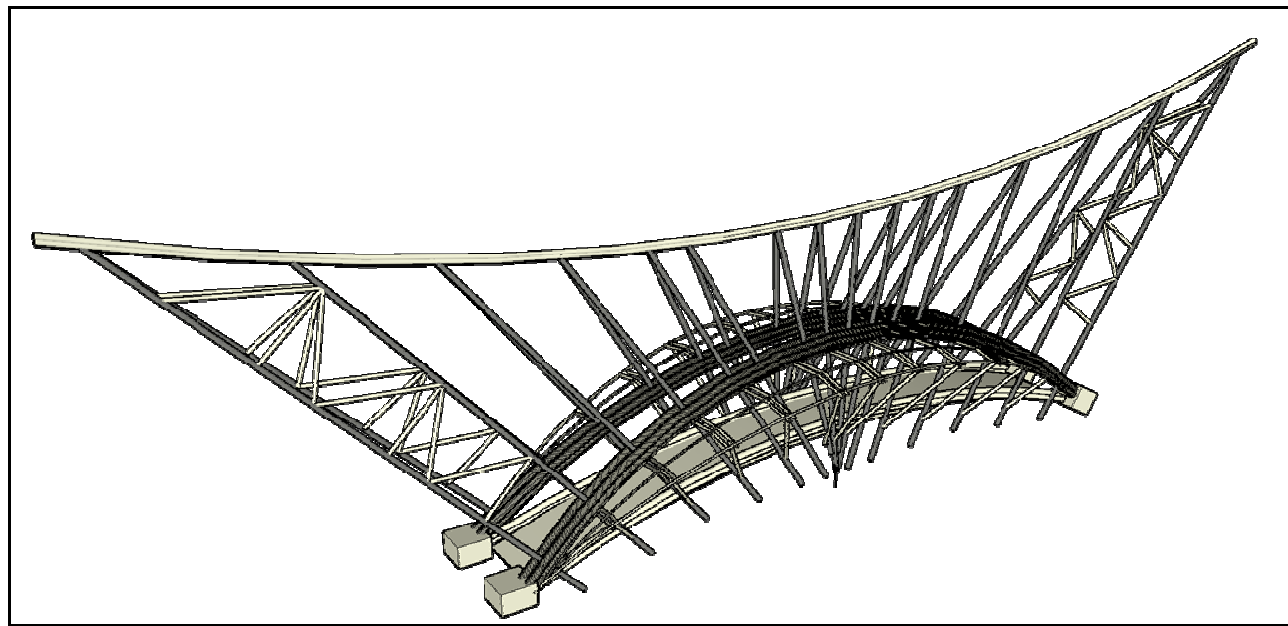

Figure 10: The millennium bridge structural model, source: self-documentation 
There are double arches for this bridge and they present themselves as main structure for the whole bridge, first one arch is for supporting the roof purpose, while the other arch one is for upholding the floor construction. The form of the roof comes from traditional Batak tribe's house, which has curvaceous ridge and cantilevered rakes in edge part of both ends, this form is implemented for this bridge roof form. These two double arches are the main structure for whole bridge, and they come from the big dimension of bamboo culm. It appears clearly that the architect picked very big dimension of bamboo culms to support as main structure. One type of arches contains of two big bamboo culms, and each of culms elongated for the twenty-three-meters span. The roof construction part has special truss system in the edge of the bridge, which is significant to support the tilted diagonal bamboos (cantilevered part). The truss section has its own connection, but in the below table here the bridge component will be reviewed one by one part:

Table 1: The Millennium Bridge Bali Joinery components

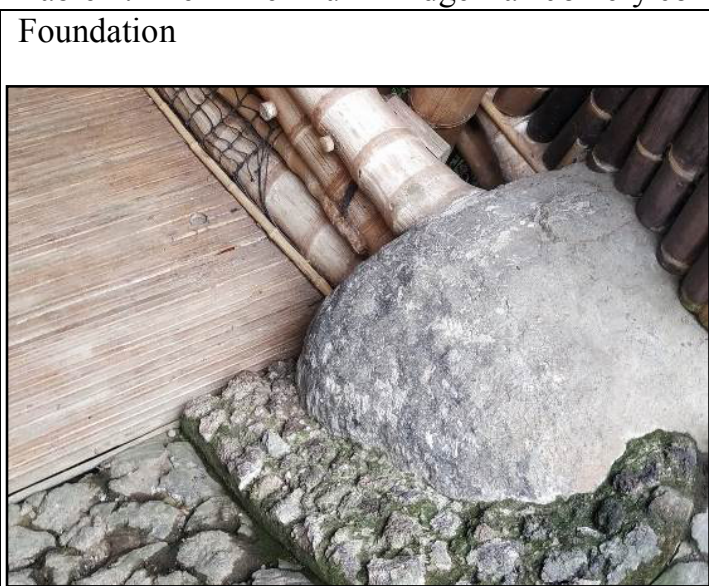

Figure 11: Millennium bridge's foundation

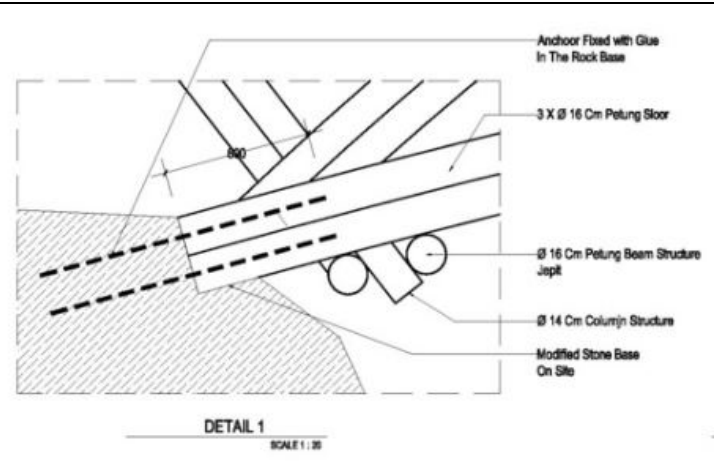

Figure

12: foundation

detail, source: www.archdaily.com/884632/the-milleniumbridge-ibuku/5a1flb68b22e387867000105-themillenium-bridge-ibuku-sectiondetails?next_project $=$ no

The foundation part is a kind of pedestal foundation with the material of stone, it appears actually as a modified stone. When it comes the joint to the bamboo arch, the bottom of bamboo is filled with steel anchors, that penetrated to the modified pedestal. It appears as reinforcement and a kind of joints for foundation. One arch appears not as a single arch, but it presents as a cluster arch that contains of two bamboo culms. This modified pedestal happened with the considering of avoiding the bamboo arch for touching the ground/soil or avoiding in contact with watery place. They made this kind foundation in order to make the bridge last longer. It proofed this bridge has been standing for more than thirteen years (2008-2021)

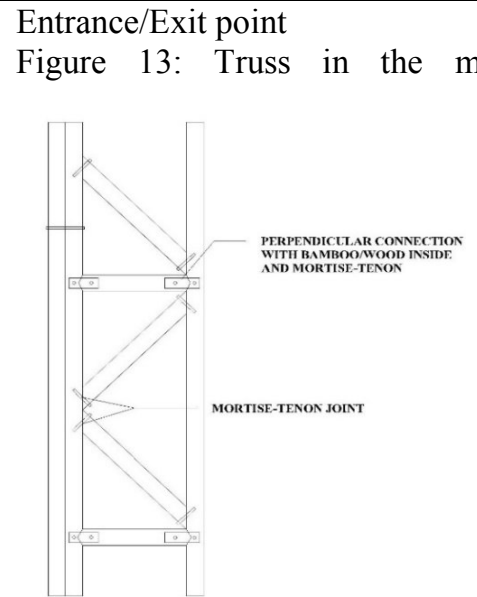

Source: self-documentation
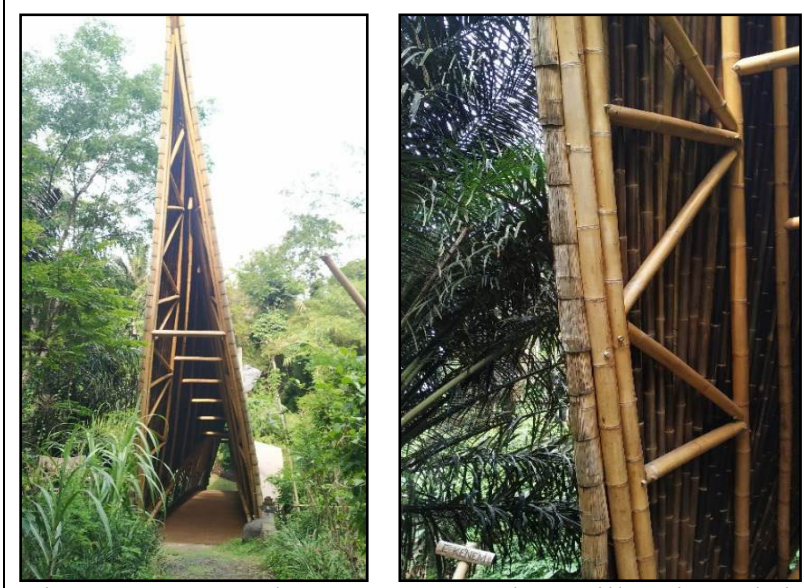

Figure 14: Bamboo truss on the millennium bridge Source: self-documentation

At the entrance and at the exit point of the bridge, there is special construction. In each ending part, the diagonal culm has a truss system. This diagonal culm can also be known as cantilevered part of the roof. The joints in this part are mortise-tenon system or dowel system. The joints in this truss system appears as perpendicular connection with wooden/bamboo dowel and for the diagonal part of the truss, the joint just using mortise tenon joint system. 


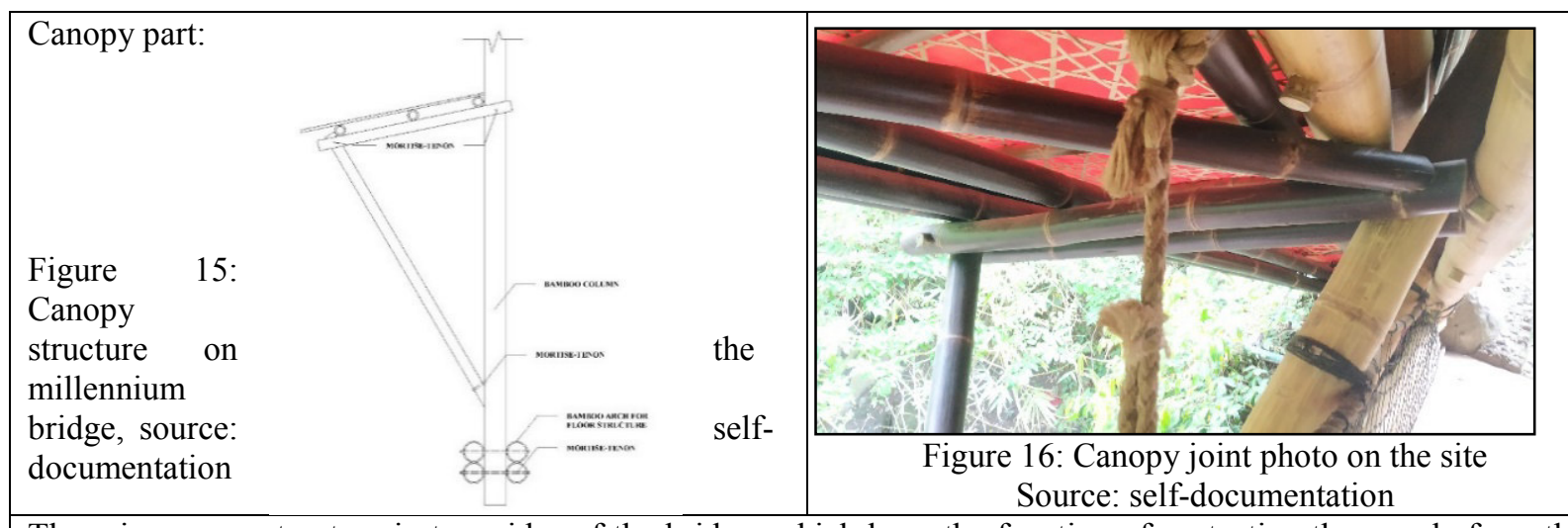

There is canopy structure in two sides of the bridge, which have the function of protecting the people from the rain, this cantilever is not the main structure, but quite significant for the people. The structure is sticked to the main post/vertical structure, and as the Figure present to us, the joint use wooden/bamboo dowel system, this canopy structure contains of two members that clamp to the main structure (column). As it can be noticed, the type of the cantilever structure is different type of bamboo, the color is darker than the main structure and it has smaller dimension.

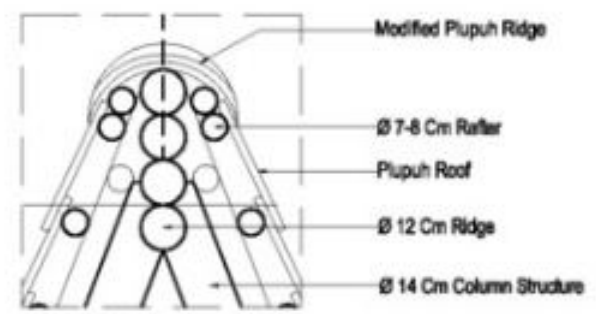

.archdaily.com/884632/the-millenium-bridgeibuku/5a1f1b83b22e384eb10002e0-the-milleniumbridge-ibuku-section-details?next_project=no

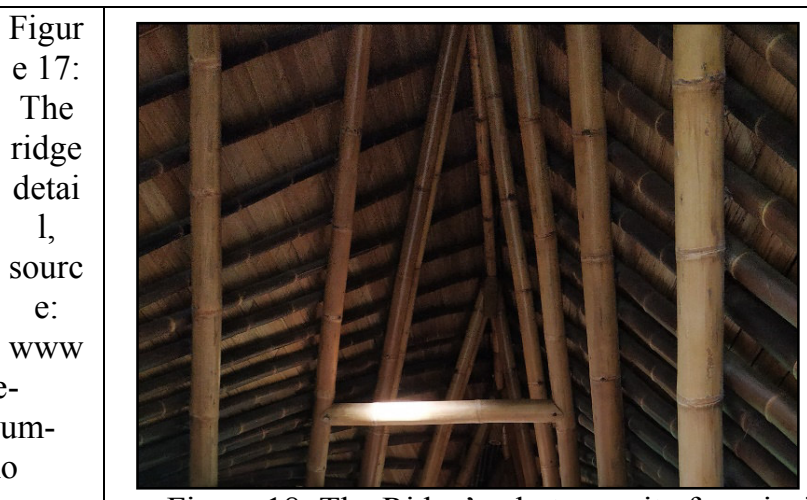

Figure 18: The Ridge's photo on site from inside Source: self-documentation

The top of the roof is quite unique. In one side, the ridge has curvaceous shape that is made by curved bamboo culm which is supported by the vertical structure. The ridge itself contains of four members, set in vertical order, the connection with the easel is also mortise-tenon, but the easel was cut to put the ridge inside. It is not ordinary, because as in literature said, for the ridge, it could use 'tongue' connection that could be bent. The column structure meets the ridge also with the mortise-tenon system.

\section{Middle bridge part:}

Figure 19: middle bridge drawing detail, source:

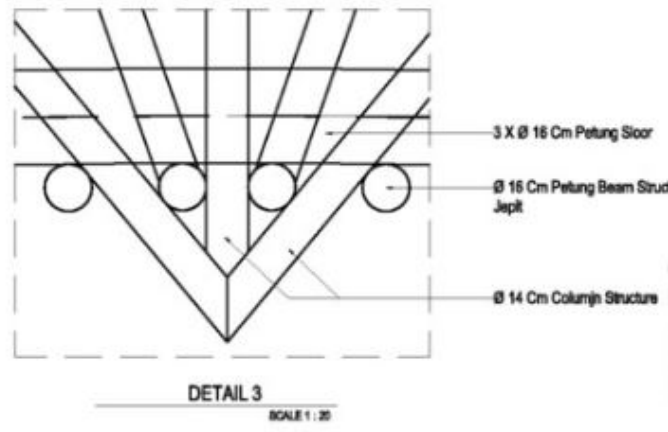

//www.archdaily.com/884632/the-millenium-bridgeibuku/5a1f1b83b22e384eb10002e0-the-milleniumbridge-ibuku-section-details?next_project $=$ no

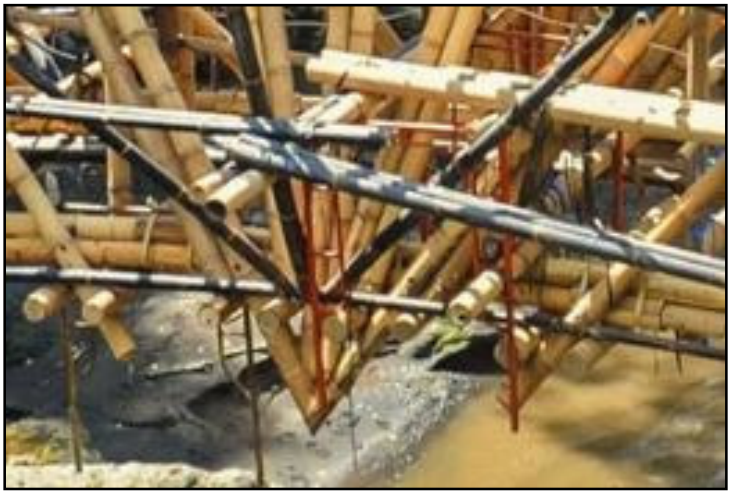

Figure 20: Middle bridge photo Source:https://ideas.ted.com/gallery-these-buildingsare-made-of-bamboo/ 
At the middle of the bridge, there is special connection that is located in the bottom of the floor structure. This connection happened due to different tilting bamboo culms that is set vertically. There are five components that connect to one point together, the detail can be looked from the Figure and this is special connection. The outmost bamboo culms connect together with tilted cuts and connects together with mortise tenon system and using glue, while the middle column rest on the top of this connection. The rest of bamboo column rest on the floor structure.

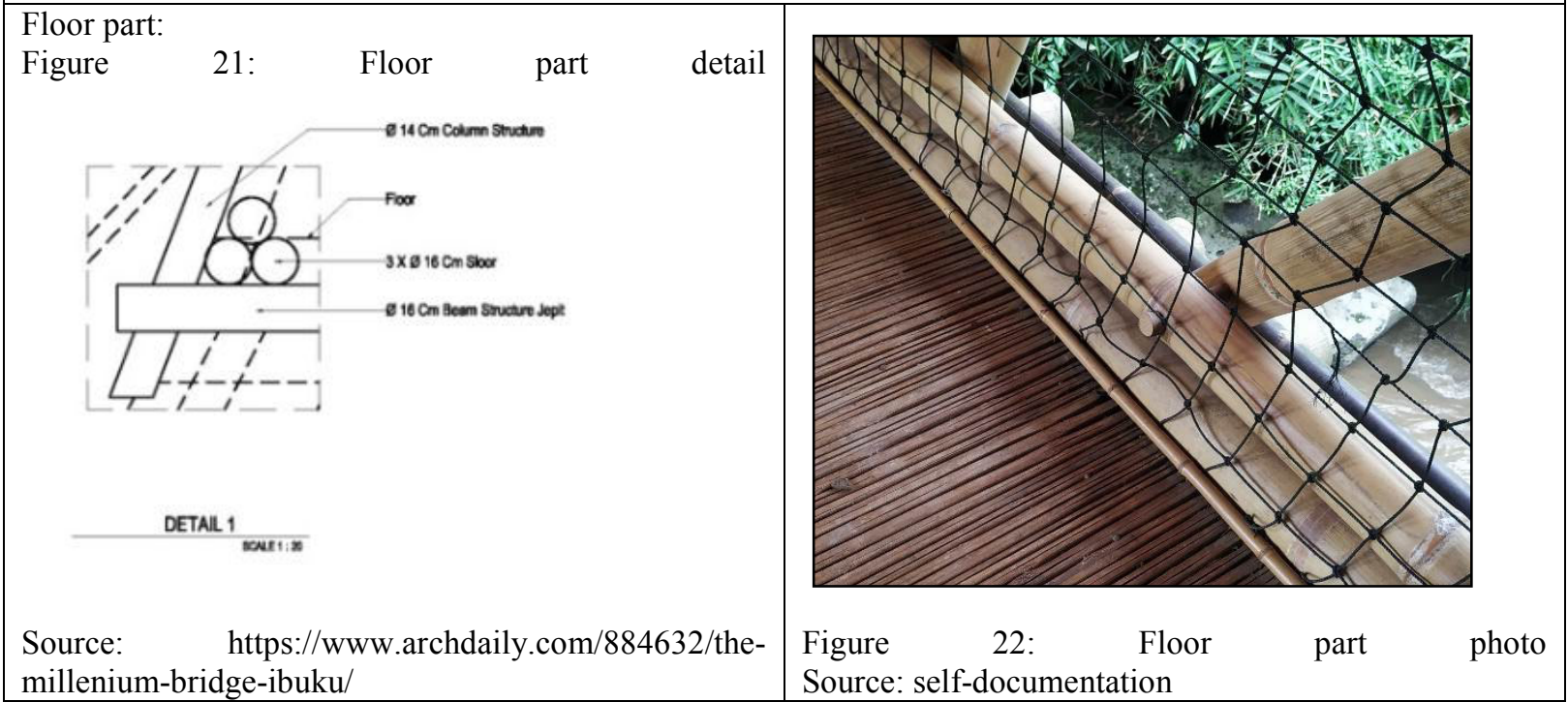
millenium-bridge-ibuku/

Source: self-documentation

The floor part is sustained by arch as structure too, it contains of three culms for an arch. The joint with the vertical/diagonal columns using dowel/wedge system. This dowel is made by bamboo or timber. The floor itself is made by split bamboo that is set in a row and pinned together for the stiffness.

\section{Conclusion}

The bamboo architecture in the projects Green School Bali, especially in The Millennium Bridge has its own uniqueness. The joints mostly between mortise-tenon system or using dowel to connect each part. It obviously makes sense because this bridge mostly has the kind of truss system structure and double arches. From the main structure, arch, till connecting to the roof structure and to the canopy structure; mortise-tenon and dowel system are so popular and correct for applying. It is fitting in when these systems are applied to the bridge, because the bamboo structure over time while using mortise-tenon or dowel system will not destroy the integrity of bamboo culms and can be last longer. Moreover, there is no lashing method for this bridge. Regards to the conformity to the literatures, the joints system has achieved the bamboo joint's appropriateness. It is deserved that this building has already met its thirteen years old till now.

\section{References}

Frick, Heinz. (2004) Ilmu Konstruksi Bangunan Bambu, $6^{\text {th }}$ edn. Yogyakarta: Kanisius Publishing, 23-29.

Ha, Thu-Huong. (2015) Gallery: These buildings are made of... bamboo? [Online]. Available at: https://ideas.ted.com/gallery-these-buildings-are-made-of-bamboo/. (Accessed: 3 February 2021)

Ibuku. (2011) The Millennium Bridge/IBUKU [Online]. Available at: https://www.archdaily.com/884632/themillenium-bridge-ibuku. (Accessed: 3 February 2021)

Janssen, Jules J. A. (2000) Designing and Building with Bamboo, $20^{\text {th }}$ edn. Netherlands: Technical University of Eindhoven, 97\&125.

Meinhold, Bridgette (2011) Cocoon-Like Vertical Bamboo Towers are High Tech and Primitive at the Same Time [Online]. Available at: https://inhabitat.com/vertical-bamboo-towers-are-high-tech-and-primitive-atthe-same-time/bamboo-housing-saint-val-laurent-11/. (Accessed: 3 February 2021)

Schröder, Stéphane. Basic Principle and Techniques [Online] https://www.guaduabamboo.com/blog/joining-bamboo. (Accessed: 3 February 2021)

Widyowijatnoko, A., \& Aditra, R.F. (2018). "Great Hall of Out ward Bound Indonesia: Case study of Structural Approach in Bamboo Architecture", Semantic Scholar, [online]. Available at: https://www.semanticscholar.org/paper/Great-Hall-of-Outward-Bound-Indonesia\%3A-Case-studyWidyowijatnoko-Aditra/9f7f719fc270445b882fa9def7c4159550860b50 (Accessed: 3 February 2021)

\section{Diego Puja Mring Gusti}

Diego Puja Mring Gusti was born in Bandung city, West Java, Indonesia, in 1993. He received Architectural 
Engineer degree from Universitas Katolik Parahyangan, Indonesia in 2016. Right now, he is pursuing his master degree in Architecture in Southeast University, P. R. China. He interests in architectural designing world, especially when it comes to sustainability and eco-friendly issue.

\section{Han Xiaofeng*}

Han Xiaofeng is a PHD Associate Professor of the school of architecture in Southeast university, Nanjing, China. He is first author's academic professor in Southeast University. 